\title{
El problema de la opinión pública en el pensamiento sociológico de Habermas, Luhmann y Bourdieu: disquisiciones políticas, comunicacionales e ideológicas sobre un fenómeno ¿democrático?
}

\author{
Ana Pamela García ${ }^{1}$ \\ Fecha de recepción: 17 de septiembre de 2014 \\ Fecha de aprobación: 20 de octubre de 2014

\begin{abstract}
Resumen
Se discute aquí el carácter de la "opinión pública" como categoría conceptual en el marco de las perspectivas de Jürgen Habermas, Niklas Luhmann y Pierre Bourdieu. Sus lecturas sobre este fenómeno psico-socio-político y comunicativo, todavía polémico dentro del debate sobre las formas sociales de la democracia representativa, se abordan considerando: primero, la relación de continuidad de sus propuestas con las principales tradiciones de la teoría social contemporánea; segundo, su potencialidad crítica para un esclarecimiento sociológico de la relación entre opinión pública y "medios masivos de comunicación"; tercero, sus diferentes concepciones del "espacio público" como categoría central o residual en la comprensión del sentido de la acción social.
\end{abstract}

Palabras clave: opinión pública, medios masivos, espacio público, sociología política, democracia.

\section{The problem of public opinion in the sociological thought of Habermas, Luhmann and Bourdieu: political, communicational and ideological disquisitions on a "democratic?" phenomenon}

Abstract

This paper discusses the character of "public opinion" as a conceptual category within the perspectives of Jürgen Habermas, Pierre Bourdieu and

\footnotetext{
Dra. en Estudios Sociales de América Latina (mención sociología) e Investigadora de CONICET. Córdoba Capital / CIECS, CONICET / UNC - Argentina (Centro de Investigaciones y Estudios en Cultura y Sociedad, Consejo Nacional de Investigaciones Científicas y Técnicas / Universidad Nacional de Córdoba). pamela. pazgarcia@gmail.com
} 
Niklas Luhmann. Their literature about this psycho-socio-political and communicative phenomenon, still controversial in the discussion on the social forms of representative democracy, are addressed considering: First, the relationship of continuity of their proposals with the main traditions of contemporary social theory; second, its critical potential for a sociological clarification of the relationship between public opinion and "mass media"; third, their different conceptions of "public space" as a central or residual category in understanding the meaning of social action.

Keywords: public opinion, mass media, public space, political sociology, democracy

\title{
O problema da opinião pública no pensamento sociológico de Habermas, Luhmann e Bourdieu: discussões políticas, comunicacionais e ideológicos sobre um fenômeno ¿democrático?
}

\begin{abstract}
Resumo
Discute-se aqui o caráter da "opinião pública" como categoria conceitual no marco das perspectivas de Jürgen Habermas, Niklas Luhmann e Pierre Bourdieu. Suas leituras sobre este fenômeno psico-sócio-político e comunicativo, ainda polêmico dentro do debate sobre as formas sociais da democracia representativa, abordam-se considerando: primeiro, a relação de continuidade de suas propostas com as principais tradições da teoria social contemporânea; segundo, sua potencialidade crítica para um esclarecimento sociológico da relação entre a opinião pública e "meios massivos de comunicação"; terceiro, suas diferentes concepções do "espaço público" como categoria central ou residual na compreensão do sentido da ação social.
\end{abstract}

Palavras-chave: opinião pública, meios massivos de comunicação, espaço público, sociologia política, democracia.

\section{Introducción}

Desde un nunca acabado retorno a conceptualizaciones paradigmáticas para la sociología, como la racionalización del poder, la dominación ideológica y la conciencia colectiva, en los esfuerzos de síntesis teórica de Habermas, Luhmann y Bourdieu pueden reconocerse lecturas específicas del fenómeno de la "opinión pública" (OP), claves para una discusión sobre las condiciones democráticas de la comunicación política contemporánea. Los enfoques de estos autores, que podríamos denominar con justicia como "neoclásicos" de la teoría sociológica, nos remiten a Francia y Ale- 
mania como centros históricos de las trayectorias observadas por la teoría social europea a lo largo del siglo XX, en el marco de una renovación de perspectivas analíticas nunca radical respecto de referentes clásicos, como Max Weber, Karl Marx y Emile Durkheim. Sin dejar de advertir distancias entre sus sistemas teóricos y posicionamientos epistemológicos, particularmente manifiestas en la posibilidad de existencia y vigencia de un "espacio público" (EP) democrático, el contrapunteo desarrollado intenta aportar a la articulación de una sociología de la OP como ámbito analítico, capaz de reconocerles una significativa complementariedad en línea con la condición dinámica de este objeto de estudio.

\section{Habermas: el poder comunicativo de la OP y el EP como su contexto de realización política}

Habermas entiende a la OP como una "red para la comunicación de contenidos y tomas de postura" de "horizontes abiertos, porosos y desplazables" (1998, p. 440). Procurando conservar la complejidad sociopolítica del concepto, para el autor se trata de un fenómeno tan elemental como el actor humano y su acción social individual o grupal. En este sentido, la OP no podría entenderse en términos netos como sistema, institución u organización, ni tampoco como entramado normativo o psicosocial de actitudes, disposiciones, roles, etc. Habermas toma el concepto como núcleo de una teoría crítica de la sociedad y una teoría normativa sobre la democracia, definiéndolo en virtud de su relación constitutiva con el EP de acceso de la ciudadanía al debate social:

En cada conversación en la que los individuos privados se reúnen como público se constituye una porción de espacio público. (...) Los ciudadanos se comportan como público, cuando se reúnen y conciertan libremente, sin presiones y con la garantía de poder manifestar y publicar libremente su opinión, sobre las oportunidades de actuar según intereses generales. En los casos de un público amplio, esta comunicación requiere medios precisos de transferencia 
e influencia: periódicos y revistas, radio y televisión son hoy tales medios del espacio público. (Habermas, 1973, p. 61, citado en Boladeras Cucurella, 2001, p. 3).

Se aprecia entonces la presencia de dos condiciones para la existencia de la OP dentro de la concepción habermasiana: el EP como ámbito de libre expresión de las opiniones de la ciudadanía, y los "medios masivos de comunicación" (MMC) para la transferencia e influencia de las opiniones ciudadanas dentro de dicho espacio. Al interior del proceso de comunicación social en el que la OP se construye, también es importante distinguir a esta última de las opiniones "cuasi públicas", opiniones privadas de referentes o líderes de opinión, que cuentan con el doble privilegio de ser mediatizadas por los MMC y legitimadas al reconducirse a través de instituciones políticas. Ambos espacios de opinión se conectan mediante una "notoriedad pública representativa o manipulativamente desarrollada", ejercida por estos MMC, y que "solo es posible en una magnitud sociológicamente relevante, por la vía de la participación de las personas privadas en un proceso de comunicación formal" (Habermas, 1981, p. 272). Subrayando la necesidad de evaluar empíricamente el grado de reciprocidad entre ambos tipos de opinión, Habermas destaca que para una teoría sociológica de la OP esto es de una importancia decisiva, ya que "proporciona los criterios para juzgar una dimensión que es la única en la que la opinión pública puede formarse en las condiciones de una democracia de masas" (Habermas, 1981, pp. 272-273).

En Historia y crítica de la opinión pública, Habermas (1981) realiza un minucioso seguimiento del origen y desarrollo del concepto entre los siglos XVIII y XIX, tomando como tipo ideal a la publicidad burguesa y analizando su evolución en paralelo a la transformación del EP como su ámbito de expresión. Si bien este análisis socio-histórico refiere al contexto europeo, no puede desconocerse el potencial esclarecedor de su crítica sociológica sobre el tratamiento que ha recibido el concepto. Por un lado, en el marco de perspectivas liberales y como "ficción" 
del Estado de Derecho, la OP habría sido identificada con la voluntad de una ciudadanía activa, canalizada a través de los partidos políticos como sus más efectivos representantes. Para el autor, esta primera visión presenta simplificaciones y aspiraciones de generalidad, que soslayan el proceso intersubjetivo de formación de la voluntad política independiente de tales contextos organizacionales. Por otro lado, también advierte sobre la "disolución socio-psicológica" del concepto, producto de la extensa tradición de investigaciones en comunicación masiva, que habrían "arrancado" al fenómeno de su contexto funcional dado por los procesos de discusión racional en el EP, reduciéndolo a un producto ahistórico de estructuras de comunicación masiva. Recuperando al respecto una crítica del propio Lazarsfeld ${ }^{2}$, Habermas reivindica la importancia político-democrática de la OP, destacando su función ideal como eje de cohesión social y legitimación política.

Así, el funcionamiento legítimo del sistema democrático depende de la dirección administrativa que la OP imprima a sus manifestaciones expresivas en el EP. Este espacio se hallaría constituido por una red de estructuras, cuyo "poder comunicativo" influye en las decisiones del subsistema político. Desde una visión discursiva de la democracia y con base en una filosofía intersubjetivista de los procesos políticos, para Habermas es en este contexto en el que la soberanía popular "surge de las interacciones entre la formación de la voluntad común, institucionalizada con técnicas propias del Estado de Derecho, y los espacios públicos movilizados culturalmente" (Habermas, 1999, p. 245). De este modo, su pensamiento teórico político se enmarca dentro de un proyecto reconstructivo de la democracia moderna que, a partir

\footnotetext{
2 Se hace referencia aquí a la postura del sociólogo Paul Félix Lazarsfeld (19011976), referente de la MCR (Mass Communication Research) cuyos aportes más significativos al campo de la investigación empírica en comunicación política se producen a mediados del siglo XX, en contemporaneidad con los desarrollos críticos de la Escuela de Frankfurt y asumiendo una postura analítica e ideológica constrastante con esta última.
} 
de un modelo deliberativo, recupera contenidos normativos de las perspectivas republicanas y pluralistas, sin dejar de referenciarlos en el actual contexto de mediatización de la comunicación social. En esta dirección, sus obras de contenido más político-jurídico se conectan con sus estudios sobre el desarrollo sociohistórico del EP, en tanto esfera donde la OP se consolida como clave de legitimación política.

En "Facticidad y Validez", Habermas (1998) articula las proposiciones centrales de su Teoría de la acción comunicativa con sus reflexiones en torno al derecho y la filosofía política, renovando su perspectiva sociológica sobre la democracia con base en los aportes de la Teoría del discurso. Aquí la sociedad civil es asimilada por el autor a la infraestructura de un EP autónomo, reposicionado tanto respecto del Estado como del mercado, bajo una concepción de la política con connotaciones normativas que, a su entender, resultan "más fuertes que el modelo liberal pero más débiles que el modelo republicano" (Habermas, 1998, p. 374). Al respecto, la idealidad normativa de su planteo no desconoce el problema de la mediación, inherente a las estructuras de comunicación pública. La OP se transforma en "poder comunicativo" como resultado de una racionalización discursiva de las decisiones políticas, que significa tanto más que mera legitimación -del poder político bajo una concepción liberal- como menos que constitución del poder -desde una óptica republicana de la sociedad como comunidad política- (Habermas, 1998, p. 376; 1999, p. 244). Así, corrientes de comunicación e interacción que fluyen de modo anárquico, le permiten al EP actualizarse sensiblemente en la percepción y tematización de cuestiones colectivas. Sin embargo, Habermas advierte que en este proceso la distribución del saber en el EP se halla signada por la selectividad con que intervienen los MMC en la circulación del sentido social, cuya interposición introduce inevitables asimetrías y "desiguales oportunidades de acceso a la producción, validación, regulación, control y presentación de los mensajes" (Habermas, 1998, p. 404). 
El "poder comunicativo" de la ciudadanía se halla entonces limitado por las condiciones estructurales de la sociedad civil, relativas tanto a sus capacidades individuales como a ciertas restricciones sistémicas que inciden en la eficacia social de los procedimientos de deliberación vigentes. Para Habermas, un EP capaz de encontrar resonancia en el sistema político, depende de este "anclaje social" para desarrollar procesos espontáneos de formación de la OP. Tales condiciones se encontrarían enraizadas en el contexto del mundo de la vida, como "fuente de operaciones interpretativas" (Habermas, 1998, p. 84) que, reproducidas por la acción comunicativa, limitan "desde dentro" las capacidades de entendimiento intersubjetivo y coordinación social de la acción política. En sociedades complejas, donde conviven y compiten diversos proyectos de mundo de la vida, la racionalidad comunicativa a través del lenguaje se constituye además en fuente primordial de la integración social. Por la vía de una política deliberativa, los ciudadanos pueden ejercer intercambios comunicativos que permitan regular cooperativamente su convivencia, ejerciendo la autonomía política de concederse a sí mismos "el derecho de permanecer extraños los unos de los otros" (Habermas, 1998, p. 386). El entendimiento discursivo garantizaría así el sostenimiento de una cultura abierta a la complejidad, motivando a los actores sociales para una constante actualización de sus horizontes de sentido. Esta concepción de Habermas del sistema político como ámbito en retroalimentación con las estructuras del mundo de la vida, se convierte en otro eje fundamental de su sociología política reconstructiva de la democracia.

\section{Sociología reconstructiva de la democracia}

El esfuerzo de síntesis teórica de Habermas procura trascender una mera institucionalización del modelo de democracia liberal, cuya falla sustancial a su entender ha sido dar por supuesta la voluntad pública de la ciudadanía. A lo largo de su obra, la tensión entre realidad sociopolítica contemporánea e idealidad normativa moderna permanece irresuelta, alimentando diferen- 
tes etapas de su pensamiento. Aun cuando se le reprocha un alto grado de abstracción y cierta "anemia práctica"3 , la profundidad que reviste su tratamiento de categorías conceptuales complejas, como OP y EP -a las cuales adscribe un contenido tanto sociológico como político, comunicacional y filosófico-, evidencian la amplitud y transversalidad de su argumentación teórica. El autor incorpora a su análisis tanto enfoques clásicos de la teoría social como categorías conceptuales de las tradiciones liberal o republicana, incluyendo los ejes de la discusión sobre la democracia planteada entre corrientes empiristas, procedimentalistas y pluralistas, respecto de las cuales informa sus planteamientos o alternativamente toma distancia.

Habermas aporta entonces al recorrido planteado dos claves interpretativas sustanciales. Primero, su énfasis en el doble condicionamiento normativo y discursivo de la voluntad política, completa y actualiza la configuración ideal del modelo democrático representativo, recuperando el papel de la OP como instancia de mediación social y la esfera del EP como su ámbito de desarrollo. Segundo, su programa reconstructivo de la teoría democrática ${ }^{4}$ traduce comunicativamente conceptos nodales como el de "soberanía popular", resignificando su sentido complejo desde un esfuerzo de articulación entre condiciones sistémicas y microsociológicas de la acción social.

\footnotetext{
Esta crítica a la construcción teórica de Habermas es mencionada por Velasco Arroyo (Habermas, 1999), en su introducción a La inclusión del otro. Estudios de teoría política. Este traductor y estudioso de la obra del autor destaca cómo este ha procurado compensar su elevado grado de generalidad y "acusado aliento sistemático" (Habermas, 1999, p. 14), por medio de referencias empíricas que con frecuencia vuelca en conferencias o ensayos periodísticos.

4 Dentro de su sociología de la democracia, Habermas procede en términos reconstructivos, recuperando aquellos contenidos normativos donde fuera posible identificar "partículas y fragmentos ya encarnados de una 'razón existente" (Habermas, 1998, p. 363). Al respecto, Jiménez Redondo destaca su propósito de descubrir si las ideas de la Ilustración son letra muerta ante una complejidad social que las desborda, o por el contrario son todavía operativas en la interpretación del proceso político existente. Así, para Habermas, una teoría que procede reconstructivamente afronta la tensión y el riesgo de reconstruir la "idealidad inmanente a la facticidad de la realidad" que se analiza (Habermas, 1998, p. 13).
} 
En cuanto al primer aspecto señalado, cabe resaltar que la reconstrucción habermasiana del concepto de OP no desconoce las transformaciones históricas del EP, dadas sustancialmente con el advenimiento de las comunicaciones masivas. Aun cuando no profundiza en el papel social de los MMC -como sí lo harán Luhmann en su análisis de la construcción de la realidad social y Bourdieu en su posición alerta hacia la eficacia simbólica del poder político-, Habermas metaboliza la crítica frankfurtiana a la razón técnica y su oposición a la razón práctica, llamando la atención sociológica sobre la manipulación experta tanto de las magnitudes y tendencias de la OP como de sus procesos de formación dentro de la cultura política. Por otro lado y siguiendo la lectura de Nora Rabotnikof (2005) acerca del lugar de mediación sociopolítica ocupado por la esfera de lo público, el EP, como supuesto vertebrador del planteo habermasiano, continuará siendo revisado por el autor y así "será alternadamente mediación entre sociedad y Estado, entre mundo de la vida y sistema, entre redes de solidaridad o asociaciones y estructura institucional" (Rabotnikof, 2005, p. 166).

Tomando como segundo gran aporte del planteo de Habermas el esfuerzo de traducción comunicativa sobre el que funda su proyecto sociológico reconstructivo, se destaca la actualización del autor de la idea de "soberanía popular". Lejos de una negación radical de esta noción, común a enfoques críticos que advierten en ella el núcleo duro de una lógica contractual y liberal de la representación política productora de profundas desigualdades, Habermas intenta ajustar su sentido normativo a las condiciones de pluralidad y reivindicación de las diferencias propias de un orden postradicional. Para el autor, se debilita el alcance de una racionalidad comunicativa que quiebra su lazo exclusivo con la moral y "se despliega en los procesos informales de construcción de opinión y voluntad" (Rabotnikof, 2005, p. 201), enfatizando su preocupación prioritaria por la legitimidad vinculante discursiva y racionalmente fundada de las estructuras normativas del orden social. Asimismo, su concepción de esta problemática política en 
clave comunicativa actualiza el debate sobre la integración social, cuestión que tradicionalmente ha desvelado a la sociología desde sus orígenes como disciplina en el siglo XIX. Dentro de la arquitectura analítica de Habermas, la OP como fuerza social y el EP como su contexto de desarrollo, son esferas reproducidas por una acción comunicativa que, desde el mundo de la vida intersubjetivo, resiste la colonización burocrática del sentido social. En este punto, su crítica enfatiza la debilidad metodológica del funcionalismo sistémico, al dar por cerrado y realizado este proceso de burocratización, ya previsto por la tesis weberiana de la creciente racionalización social. Para el autor, este supuesto desnuda "pretensiones absolutistas", manifiestas incluso en planteos neo-funcionalistas, dado que, mientras "este 'mundo administrado' era, para Adorno, una versión de máximo espanto, para Luhmann se ha convertido en un presupuesto trivial" (Habermas, 1987, p. 442, citado por Rabotnikof, 2005, p. 199). Esta última crítica trae a la superficie la influencia profunda en su pensamiento de la Teoría crítica frankfurtiana, bajo la nota personal de un oficioso optimismo respecto de las potencialidades de la discusión racional como fundamento de la política.

\section{Luhmann: la función de tematización de la OP y su enfoque contingente}

En el marco de las teorías matemáticas y cibernéticas que informan su planteo sistémico, para Niklas Luhmann la OP es "el entorno interno de las organizaciones e interacciones políticas" (Luhmann, 2007, p. 149). En este sentido, surge y se desarrolla como una contingencia política sustantivada, "como un sustantivo al cual se le confía la solución de reducir la multiplicidad subjetiva de lo política y jurídicamente posible" (Luhmann, 1980, p. 89, citado por Rabotnikof, 2005, p. 249). Esta conceptualización funcional destaca la relación entre OP y decisión política, en virtud de la cual la OP no sería el disparador original de la voluntad popular sino el marcador de su ámbito de discusión, elaborando 
los temas que serán objeto de decisión política. Como instrumento de reducción de la contingencia, la OP establece el marco de sentido para las operaciones internas del sistema político, seleccionando temas que estructuran y reducen la complejidad de los procesos de comunicación política. Así, la OP es entendida por Luhmann como un subsistema altamente dinámico, cuya fluctuación y movilidad se conecta con la duración y variabilidad de temas, no de opiniones individuales y corrientes de opinión que han preocupado tanto a las teorías demoliberales como a la psicología de las masas.

En cuanto a la tradición, este concepto de opinión pública renuncia a toda implicación de racionalidad así como a cualquier manifestación de irracionalidad específicas a la 'psicología de las masas' (...) los juicios de racionalidad son siempre juicios del observador. Y si queremos conocer lo que alguien afirma como racional o irracional, tenemos que saber los criterios, debemos observar al observador. (Luhmann, 1990, p. 210, citado por Rabotnikof, 2005, p. 256)

Para comprender el lugar que ocupa el concepto de OP dentro del sistema teórico de Luhmann, resulta fundamental considerar las propiedades de su modelo de sociedad compleja. A su entender, "los sistemas sociales se sirven de la comunicación" (Luhmann, 1995, p. 25) para reproducirse y, en este sentido, la sociedad es un universo autocontenido capaz de realizar todas las operaciones necesarias para una dotación social del sentido. Así, la sociedad es un orden emergente, en el que sentidos prelingüísticos son generalizados por la acción simbólica del lenguaje, permitiendo el acople de las conciencias individuales, desde una comunicación social que, vía MMC, logra independizarse de la interacción personal.

Por su parte, los MMC son comprendidos por el autor como "todas aquellas disposiciones de la sociedad que se sirven, para propagar la comunicación, de medios técnicos de reproducción 
masiva" (Nafarrante, en Luhmann, 2007, p. 2). Como uno de los sistemas surgidos del proceso de diferenciación interna de la sociedad, los MMC reproducen una forma social específica de comunicación, en la cual la interacción cede el paso a una escenificación en que "los efectos producidos por todos los participantes" ya no son "ni efectivos ni visibles" (Luhmann, 2007, p. 23). Aun cuando su teoría es criticada por la asepsia con la que su concepción funcional trata el problema del sentido del comportamiento social, este desarrollo de la función de los MMC muestra profundas implicancias para el estudio de los problemas de la cognición y la recepción activa de las comunicaciones. Lejos de una visión tecnologizante, Luhmann afirma distanciarse de la materialidad de las disposiciones técnicas para concentrarse en sus efectos. Su énfasis en la comprensión, entendiendo que la "acción comunicativa" no es tal si no produce el desprendimiento de comunicaciones posteriores, lo conduce a advertir una debilidad clave en la prescindencia de la interacción de las comunicaciones masivas: su opacidad constitutiva, al ser "muy difícil determinar el círculo actual de receptores que coefectúan la comunicación" (Luhmann, 2007, p. 6).

Sintetizando sus principales aportes al entendimiento de la OP, se advierte que el planteo de Luhmann alimenta una visión menos condenatoria o intrigante de los MMC, aunque no por ello menos problematizadora de sus efectos sociales. Concentrando su análisis en las estructuras de sentido derivadas de los MMC, para Luhmann el impacto de la tecnología, con la consecuente omisión de la necesidad de interacción, ha producido un salto cualitativo en favor de la "autopoiesis" del sistema mediático. Este sistema logra su clausura operativa cuando se reproduce a sí mismo, para luego producir una realidad de segundo orden, en la que la "información crea un 'estado imaginario' de la sociedad" (Nafarrante, en Luhmann, 2007, p. 6). Así, desde las condiciones de operación dadas por la tecnología y dentro de un margen de intencionalidad sistémicamente atribuido, los MMC cumplirían dos imperativos funcionales: la función de "inquietar", movilizando 
estímulos cognitivos, y la función de dirigir la "autoobservación" del propio sistema social. Ambas funciones indican la metabolización en el esquema luhmanniano de algunos estudios sobre la producción noticiosa, al destacar alternativa y complementariamente la "sorpresa" y la "estandarización" como criterios selectivos aplicados por los MMC. Bajo la exigencia (autorreproductiva) de una producción permanente de novedades, dentro del sistema de los MMC ambos criterios operan para generar "valor informativo" (Luhmann, 2007, p. 44). Con independencia de cualquier teoría conspirativa, es por el efecto de la diferenciación social que estas funciones mediáticas de estimulación y autoobservación hacen posible el conocimiento social, mediante la introyección de una realidad preconstruida. De este modo es como se construye "lo que los seres humanos saben sobre la sociedad y sobre el mundo (y lo que pueden comunicar sobre ello)" (Luhmann, 2007, p. 122). Para el autor, la realidad de los MMC funciona como una observación de segundo orden (Luhmann, 2007) y por este principio entiende su duplicación como circunstancia de su elaboración.

Bajo una lógica circular y restrictiva, los MMC asimilan la contingencia y producen información valorada socialmente. En su acción impera la "selección" (Luhmann 1995, p. 29) y no la elección de formatos y contenidos, en virtud de lo cual las necesidades del sistema imponen su prioridad por encima de las preferencias periodísticas. Así, un amplio conjunto de criterios selectores -por ejemplo, la preferencia por la tensión emocionante de conflictos o la contravención de las normas, los escándalos, etc.- condicionan la reproducción de incertidumbre acerca del futuro y apuntan "contra la percepción de continuidad del mundo conocido" (Luhmann, 2007, p. 55). Se trata de una red autorreforzada de selectores, ocupada en la producción cotidiana de noticias para un sistema social que (como abstracción de nivel superior), las demanda preconfigurándolas.

En cuanto al vínculo de los MMC con la OP, de la misma manera que la función de "tematización" les cabe a los MMC para 
lograr su "acoplamiento estructural" con otros sistemas, la función de la OP es la "representación de lo público" (Luhmann, 2007, p. 151). Respecto del nivel de autonomía de estas relaciones, siempre en función de los imperativos del sistema social, la OP no es regulada por los $\mathrm{MMC}^{5}$ sino por el sistema político, aunque "sin determinarla de manera estable" (Rabotnikof, 2005, p. 251). En su vínculo fundamental con el sistema político, la OP desempeña un trabajo análogo al que los MMC realizan con los temas específicos de otros sistemas sociales: ambos entornos producen tematizaciones basadas en la selección de temas y problemas dirigidos a concentrar la atención pública, aunque en el caso de la OP esta tarea se realiza dentro del ámbito exclusivo de los procesos de comunicación política.

\section{Sociología sistémica de la complejidad estructural}

Sobre las posibilidades que un enfoque sistémico de la sociedad, profundamente articulado como el de Luhmann, abre en la comprensión instrumental de la política y lo político, cabría destacar al menos tres aspectos: primero, su noción amplia y dinámica de lo público, que desde una perspectiva sociocognitiva la descarga de la normatividad y moralidad características del EP

$5 \quad$ Desde la distinción entre las aportaciones al sistema social de los MMC y la OP, como subsistemas con lógicas específicas, para Luhmann perdería capacidad explicativa la teoría de la "espiral del silencio" desarrollada por Elisabeth NoelleNeumann, sobre la base del miedo al rechazo y la búsqueda de adecuación al entorno como respuestas humanas fundamentales. En tanto otra significativa aportación al estudio de la OP que entra en diálogo con los planteos de J. Habermas, la base psicosocial que informa la teoría de Noelle-Neumann es disuelta por los condicionamientos reproductivos de los procesos de información y comunicación advertidos desde la mirada macrosistémica de Luhmann. Considerando las funciones de estimulación y búsqueda de novedad como condiciones de la producción informativa, cabe recordar que los criterios selectores de los MMC pueden tratar las opiniones sobre los acontecimientos como si fueran acontecimientos y así "pueden realzar opiniones minoritarias precisamente porque son espectaculares, ricas en conflictividad e inclinadas a la desviación" (Luhmann, 2007, p. 129). De este modo se desmitificaría el poder de la "espiral del silencio" como lógica válida para la reproducción de la OP. 
como categoría tradicional; segundo, su reconceptualización funcional de la $O P$, que reconoce la posibilidad política del disenso, superando las ideas de voluntad y soberanía popular en extensión elaboradas por la teoría política moderna; tercero, su entendimiento sistemático de los MMC como sistema subordinado a los imperativos funcionales de la sociedad, desplegando Una noción sociocentrada de la construcción simbólica de la realidad y del sentido de la acción clave para una teoría de la comunicación masiva.

Respecto de la primera aportación señalada, si bien la noción luhmanniana de lo público diluye su politicidad específica al ser aplicable al "entorno interno de todas las interacciones y todas las organizaciones" sociales (Luhmann, 2007, p. 48) -por ejemplo, considera al "mercado" como entorno interno económico de las empresas y de forma análoga a la OP en el sistema polítiCo-, también le devuelve amplitud en el contexto de sociedades complejas, en las cuales la política se entrelaza con las demandas funcionales de otros sistemas sociales. Luhmann destaca la importancia de alcanzar un concepto de lo público que permita distinguir claramente este espacio del concepto de OP. Así, su transformación de la idea de EP pretende asumir el "cambio en las condiciones de posibilidad del espacio público liberal e ilustrado, su insuficiencia teórica y su exorbitancia política" (Rabotnikof, 2005, p. 221), introduciendo importantes recortes analíticos al proyecto político normativo de los enfoques demoliberales: por un lado, procede a la reubicación del público en el ámbito funcional del sistema político, desconectándolo de todo análisis individual o subjetivo; por el otro, distingue los ámbitos de la discusión pública y de la decisión como separación efectivamente vigente en la práctica democrática, entre decisiones gubernamentales y argumentaciones públicas o políticas.

En segundo lugar, el aporte de Luhmann a la comprensión del papel de la OP en la estructuración de las comunicaciones políticas sobre temas relevantes para la sociedad y el Estado, reconoce sus límites prácticos al considerar por igual las posibilidades de consenso y disenso. Siguiendo el análisis de Rabotnikof, se advierte 
cómo la perspectiva luhmanniana se opone a un concepto de OP que "nace del intento de dar respuesta al problema de la decisión válida, no al de la decisión posible" (Rabotnikof, 2005, p. 176), cuestionando el supuesto de unidad de la capacidad racional de los sujetos. La OP en Luhmann funciona como una red de comunicación que no fuerza la participación ni la presupone, y que, al desligarse de la idea de consenso, "plantea el problema en un nivel anterior: ¿consenso o disenso en torno a qué?" (Rabotnikof, 2005, p. 255). Aquí cobra relevancia la función de "tematización" de la $\mathrm{OP}$, en torno a la cual el autor incorpora el problema de la atención como recurso escaso en los flujos de la comunicación política. De este modo, su visión enfatiza la distancia del tiempo presente con el horizonte de época de las tradiciones político-normativas del siglo XIX, y propone reconocer que algunos conceptos teóricos se desarrollaron como conquistas históricas: "el público burgués, estilizado en la noción moderna de opinión pública, que se presentó a sí mismo como 'la sociedad'" (Luhmann, en Rabotnikof, 2005, p. 243), diferenciándose así del "público" contemporáneo que hoy supone una articulación de roles diferenciados (votante, cliente, usuario, consumidor, entre otros).

Por último, se destaca la visión sociocentrada de Luhmann respecto del papel de los MMC en la construcción de la realidad y la circulación del sentido social. Para el autor, los MMC constituyen una forma de comunicación situada en el mismo nivel de operación sistémica que la política o la economía, desempeñándose, como su nombre lo indica, como "medios" propiamente dichos. Esta perspectiva de los MMC, como sistema autorreferente y clausurado a efectos de su propia autorreproducción, invita además a cuestionar las construcciones de la ciencia social al respecto. Así, aproximándose al imperativo de reflexividad científica interpuesto por Bourdieu, Luhmann se pregunta por las categorías de análisis aplicadas y los supuestos previos subyacentes:

¿Cómo podemos nosotros (por ejemplo los sociólogos) descubrir la realidad de su construcción de la realidad? 
No se trata de ver cómo desvirtúan los mass media la realidad por la forma como presentan los hechos. Esto supondría una realidad ontológica pre-dada, objetiva y libre de toda construcción (...) comparar una construcción de la realidad con otra (...) es necesario un instrumento teórico lo suficientemente abstracto que permita colocar la teoría de los medios de comunicación de masas dentro de una teoría general de la sociedad moderna. (Luhmann, 2007, pp. 11-12).

En contra de visiones predominantemente negativas y tesis conspirativas, el autor destaca el potencial de los MMC para favorecer la aceleración del cambio social de estructuras, ofreciendo esquemas interpretativos que, a su entender, tienen la "ventaja de estructurar la memoria, pero no sujetar la acción" (Luhmann, 2007, p. 160). En todo momento, para el autor es la sociedad la que organiza la circulación del sentido, más allá de la dinámica circular de la comunicación masiva, siendo ella la que se autoobserva y autoestimula en función de temas que los MMC seleccionan y transforman en información. Así, la propuesta de Luhmann de ajustar la teoría contemporánea a la sociedad contemporánea (compleja y en extremo diferenciada), procura despegarse por igual, tanto de la tendencia apocalíptica manifiesta por algunos diagnósticos de la teoría de la sociedad de masas sobre los MMC, como de las nostalgias conservadoras de las tradiciones político-normativas sobre la OP. Desde su óptica, el concepto sociológico de diferenciación social, heredado de Emile Durkheim, apunta a "una conquista evolutiva irreversible" (Rabotnikof, 2005, p. 224), en la transición progresiva hacia sociedades cuyas estructuraciones tienden a producirse en torno a actitudes de tipo cognitivo, capaces de adaptarse más rápidamente a los cambios. En este modelo de sociedad, la aproximación cognitivista sería acorde a la complejidad política, dado que, para el autor, los problemas de sentido anteceden a los de validez o legitimidad. Así, para Luhmann, la OP no puede dominar, prescribir ni configurar modos de ejercicio 
del poder, ya que la suya no es una relación de causa y efecto, sino de estructura y proceso: "su función no consiste en lograr afirmar la voluntad popular, esa ficción del pensamiento causal simplista, sino en ordenar operaciones de selección" (Luhmann, 1993, p. 150, citado por Rabotnikof, 2005, p. 253).

En la concepción funcional de OP de Luhmann se advierte una crítica a la tradición ilustrada del pensamiento europeo, productora de marcos teóricos que, a su entender, no son actualizables en las condiciones sociales actuales. Para el autor, las características de la OP deberán comprenderse en relación con el sistema político y dentro de la sociedad específica que se trate, fuera de toda consideración genérica de las teorías demoliberales de la sociedad civil. Aun bajo una elaborada tesis de "pérdida de centralidad" de la política, como la que domina su planteo, Luhmann aporta una visión renovadora de las capacidades del sistema político, como entorno interno capaz de articular un retorno reflexivo sobre sí mismo. Con el auxilio de la autoobservación y la autoestimulación aportadas por los MMC, más la orientación resultante de la tarea de tematización desempeñada por la OP, se ampliarían las posibilidades del sistema político para procesar las necesidades de conservación o cambio social de la democracia como modelo organizativo de las sociedades contemporáneas.

\section{Bourdieu: inexistencia de la OP, desde la crítica a la eficacia política del poder simbólico}

Para Pierre Bourdieu (1973, p. 2) la OP corresponde al "estado de la opinión en un momento dado" y constituye "un sistema de fuerzas, de tensiones", cuya manifestación empírica se torna ficticia al pretender medirla con los instrumentos del marketing político, como son las encuestas y sondeos. Materializándose en las primeras páginas de los periódicos "en forma de porcentajes", para este sociólogo la OP se convierte en un "simple y puro artefacto" (Bourdieu. 1973, p. 2), una tecnología social producida 
por expertos cuyo usufructo político-ideológico es avalado por simulaciones estadísticas que ocultan su inexistencia. Ante abordajes más abstractos, como los de Habermas y Luhmann, Bourdieu comparte con ellos la preocupación por discutir un concepto fundacional e históricamente polémico para la teoría política de la representación democrática, aunque desplaza su análisis hacia la dinámica de poder observable en las condiciones sociales del fenómeno:

¿Qué es esta opinión pública que invocan los creadores de derecho de las sociedades modernas, sociedades en las cuales el Derecho existe? Tácitamente, es la opinión de todos, de la mayoría o de aquellos que cuentan, de aquellos que son dignos de tener una opinión. Pienso que la definición patente en una sociedad que se dice democrática, es decir, donde la opinión oficial es la opinión de todos, oculta una definición latente, a saber, que la opinión pública es la opinión de los que son dignos de tener una opinión. (Bourdieu, 2012, p. 1).

En virtud de la eficacia política del poder simbólico, la OP resulta de una manipulación experta con base en la premisa ideológica de su carácter representativo. Para Bourdieu, las técnicas estadísticas que materializan los estados de OP no constituyen instrumentos de conocimiento sino de acción política y su empleo tiende a devaluar otros medios de construcción colectiva, como huelgas, manifestaciones o "las mismas elecciones, cuya lógica formalmente igualitaria imitan de manera ostensible" (Wacquant, 2005, p. 30), transformando las reglas elementales del juego democrático. Como estrategia para "hacer hablar a la gente", el uso de estas herramientas tiende a sostener una confusión entre la utopía de una democracia formal -que supone que todos los ciudadanos son políticamente competentes- y las posibilidades de una democracia real, con agentes sociales que en la práctica se encuentran "desigualmente dotados y dispuestos a expresar sus puntos de vista" (Champagne, 2005, p. 115). 
Específicamente, para Bourdieu son tres los postulados que las encuestas y sondeos asumen de manera implícita, metodológicamente errónea y políticamente intencionada:

1. “Todo el mundo puede tener una opinión (...) la producción de una opinión está al alcance de todos" (Bourdieu, 1973, p. 1). Bajo un sentimiento ingenuamente democrático, se opera un "efecto de consenso" que tiende sistemáticamente a ignorar los porcentajes de ciudadanos que por diversos motivos no contestan y, por ende, no tienen opinión.

2. "Todas las opiniones tienen el mismo peso" (Bourdieu, 1973, p. 1). Esta suposición legitima la acumulación de opiniones que dentro del campo político no tienen la misma fuerza ni se desarrollan en base a las mismas interpretaciones. Formular preguntas cerradas, para Bourdieu, "conduce a no recoger opiniones sino respuestas formuladas previamente" (Champagne, 2005, p. 116).

3. "Hay un consenso sobre los problemas (...) hay un acuerdo sobre las preguntas que vale la pena plantear" (Bourdieu, 1973, p. 1). En realidad se trata de temáticas impuestas desde afuera, a las que cada individuo responde desde una interpretación propia, resultante de su competencia política (conocimiento más o menos ajustado a las definiciones dominantes en el campo político) y ethos de clase (sistema de valores interiorizados en su conducta).

"La opinión pública no existe", conferencia académica donde Bourdieu (1973) desarrolla este análisis teórico-metodológico, surge en la década del '70 como reacción ante la influencia creciente de sondeos y encuestas en el ámbito político, denunciando su empresa ideológica de autoponderarse como representativos de la voz de la ciudadanía. Desde una tendencia al alineamiento entre las lógicas política y económica, la difusión continua y descontextualizada de estadísticas, basadas en la suposición de su neto contenido democrático, alimenta una crisis en el juego político, afectando profundamente "las estructuras elementales de la percepción política y las reglas que hasta la 
fecha prevalecían en la competencia electoral" (Champagne, 2005, p. 130).

El carácter profundo de la crítica de Bourdieu al atribucionismo democrático representativo, puesto de manifiesto por dichos instrumentos, concluye en la tesis de la inexistencia de la OP bajo estas condiciones y remite a una concepción de la vinculación estratégica del campo político con el campo periodístico, centrada en los profesionales más que en los MMC como categoría abstracta y generalizada. A su entender, el periodismo interviene en la organización de la percepción social y es sobre este terreno simbólico en el que se articula la lucha política, desde la disputa entre proyectos de refuerzo o modificación de visiones y definiciones del mundo social. En relación con el campo político, así como con el científico y el intelectual, la institución periodística ocupa una "posición privilegiada" en la lucha simbólica "por hacer ver y hacer creer" (Bourdieu, 2002, p. 65), disponiendo de la potencia de los MMC para circular e imponer sus productos ideológicos. Con las encuestas -producto que hoy se adapta especialmente a las limitaciones técnicas y políticas de la producción informativa- los periodistas se empoderan como "portavoces científicamente respaldados acerca de lo que piensa realmente la gente" (Champagne, 2005, p. 128). Sin embargo, para Bourdieu (2002), esta poderosa función esconde la fragilidad de toda profesión sujeta a los imperativos del mercado, cuando entre los tratamientos mediáticos contemporáneos predomina cierta homogeneidad tendiente a hacer intercambiables sus noticias, al encontrarse aproximadamente sometidos a similares coacciones, encuestas, anunciantes, etc.

En cuanto a la democracia como sistema político, Bourdieu considera que este modelo ha sido objeto de una reificación ideológica producto de ilusiones naturalistas de las ciencias sociales, que desde cierta amnesia sobre la génesis histórico-política y conflictiva de sus instituciones, han obstaculizado su efectivo conocimiento. Sin evaluar la contingencia histórica de lo instituido, se ha tendido a radicalizar la universalidad del modelo, sin 
atender suficientemente a sus condiciones sociales de posibilidad. Al respecto, el autor destaca la necesidad de valorar las instituciones políticas, considerando que "la forma y el contenido de una acción política son inseparables del modo de existencia del grupo en el que se produce" (Bourdieu, 2005, p. 72). Desde una oposición a aquellas perspectivas demoliberales que ven al sufragio como un acto solitario, silencioso y secreto, separado de lazos sociales y corrientes de opinión, Bourdieu destaca cierta lógica fetichizada de la teoría de la representación, como problemática clave de la política democrática que operaría cristalizando significativas condiciones de desposeimiento para las mayorías. En la reproducción del orden social dominante, las estructuras políticas juegan a favor de quienes detentan el poder, mientras "los dominados no tienen más que alguna oportunidad de sustraerse a la alternativa de la dimisión (a través de la abstención) o de la sumisión a condición de escapar a la lógica, para ellos profundamente alienante, de la elección individual" (Bourdieu, 2005, p. 75). Así, el principio de agrupación por agregación de la teoría liberal de la representación, diluiría todavía más el poder soberano de una ciudadanía atomizada y reducida a la impotencia de la alternativa excluyente entre disentir o consentir.

La política democrática entrañaría la paradoja de producir una "alquimia de la representación", en virtud de la cual el poder de mediación de los representantes absorbe todo el control por las opiniones y decisiones sociales. Así, "la acción colectiva fundada sobre la delegación, en efecto, siempre está amenazada por la apropiación usurpadora" (Bourdieu, 2005, p. 77). En definitiva, se trata de una circulación circular del poder político, contradictoria con las condiciones de una expresión democrática auténticamente autónoma. Dentro de este orden (auto) referenciado y legitimado, Bourdieu advierte que la fabricación de la "voluntad general" atraviesa dos reducciones, consecutivas y complementarias en el marco de la violencia simbólica ejercida por el poder político democráticamente sustanciado: por un lado, la anulación de la singularidad de las expresiones privadas "por 
la palabra común, la opinio communis" (Bourdieu, 2005, p. 78); por el otro, la elaboración de su publicidad como ratificación de su legitimidad, solo posible "por una persona interpuesta", portadora del discurso, "reconocida, autorizada y dotada de autoridad" (Bourdieu, 2005, p. 78), representante de una minoría sin cuya intervención las mayorías quedan políticamente desposeídas.

Desde el compromiso, no solo crítico sino fundamentalmente político, manifiesto en la obra de Bourdieu, Franck Poupeau y Tierry Discepolo (2005) destacan su oposición al funcionamiento de la ciencia política como "ciencia del desposeimiento". Para Bourdieu, la "cientifización política" y la consecuente legitimidad que la intelectualidad presta a los mecanismos de dominación instituidos, se presenta como "una de las técnicas de despolitización más eficaces" (Bourdieu, 1974, citado por Poupeau y Discepolo, 2005, p. 89). En este sentido, la deconstrucción de la producción de los sondeos de OP y la crítica operada sobre sus usos sociales se dirigen "al mismo tiempo contra los investigadores que las realizan y los políticos que las convierten en argumento de autoridad" (Poupeau y Discepolo, 2005, p. 87).

Sociología develativa de las condiciones sociales de la democracia

En la propuesta de análisis de Bourdieu de la política democrática como producción social, se advierten tres aportaciones particularmente significativas: en primer lugar, su tesis de inexistencia de la OP como expresión de sondeos y encuestas se funda tanto sobre una crítica ideológica como metodológica, elaborando un análisis sociológico integrado de los aspectos teóricos y empíricos del fenómeno; segundo, en el plano epistemológico y metateórico se destaca su esfuerzo de síntesis sociológica entre tradiciones críticas y perspectivas empíricas, enfatizando el compromiso éticopolítico de la sociología con el estudio del cambio social y de la sociología política con la discusión sobre la democracia; tercero, la inclusión de dicha discusión dentro de su enfoque explicativo dual 
de la acción social, apuesta a una superación del estudio de la cultura y la política como universos separados, abriendo el camino para la inclusión de nuevas discusiones y desarrollos transdisciplinares.

En cuanto a la primera observación sobre el análisis ideológico y metodológico de la OP expresada estadísticamente, se advierte que Bourdieu complejiza y problematiza más que cuestiona o anula el concepto de OP. Considerando el sesgo metodológico de su medición junto al uso y abuso ideológico del poder políticosimbólico, el autor advierte su empleo como estrategia para sostener una "racionalización de la acción pública" (Champagne, 2005, p. 127). En su crítica se observa cómo queda establecida una lúcida conexión entre los aportes del análisis marxista sobre la (re)producción de las formas sociales y la tesis weberiana de la creciente racionalización social. A nivel empírico, también integra la perspectiva de Durkheim sobre el anclaje social de prácticas individuales como el voto y la opinión, recuperando además las tesis de $\mathrm{H}$. Blumer ${ }^{6}$ sobre la OP, desarrolladas en el marco del interaccionismo simbólico. Desde estas síntesis e integraciones conceptuales, Bourdieu procura disolver los intentos político-intelectuales por materializar la OP legitimando el orden demoliberal. Considerando su crítica a la sobreestimación de la homogeneidad por parte de la sociología de la dominación -subyacente a una concepción del poder como obediencia, que "subestima las capacidades populares de reflexión y acción" (Maigret, 2005, p. 344)-, se destaca el esfuerzo de Bourdieu por superar una mera denuncia de esta situación en sus análisis. No obstante, se advierte que no ha profundizado en las disposiciones intersubjetivas del fenómeno, concentrándose en la escala grupal y las posiciones de fuerza que traman la OP. Si existe una OP, esta

\footnotetext{
6 Siguiendo a E. Maigret (2005) en este punto, la crítica producida por Pierre Bourdieu en la década del '70 habría encontrado inspiración en el trabajo de Herbert Blumer titulado "La opinión pública y su medición" ([1948] 1992), publicado en El interaccionismo simbólico. Perspectiva y método, capítulo 12, Barcelona, Hora.
} 
se construye por la actuación pública de grupos de interés, que "no pueden reducirse a un simple porcentaje ajeno a las tensiones que penetran la estructura social" (Champagne, 2005, p. 117). Así, las opiniones cuentan políticamente en virtud de las fuerzas sociales puestas en juego.

Para escapar a la agregación mecánica de las opiniones atomizadas sin caer en la antinomia de la protesta colectiva (...), hace falta trabajar en la creación de condiciones sociales para la instauración de un modo de fabricación de la "voluntad general" (o de la opinión colectiva) realmente colectiva, esto es, fundamentada sobre los intercambios reglados de una confrontación dialéctica que suponga la concertación de los instrumentos de comunicación necesarios para establecer el acuerdo o el desacuerdo y capaz de transformar los contenidos comunicados y a aquellos que los comunican. (Bourdieu, 2005, p. 79).

Retomando su esfuerzo de síntesis, tanto teórico-empírico como crítico-político, en segundo término se destaca la tendencia de Bourdieu a la superación de la dicotomía razón versus técnica, todavía operativa en las ciencias sociales contemporáneas. Al preguntarse por las condiciones de posibilidad de las prácticas democráticas, el autor sostiene un doble plano analítico del papel de la OP, como ficción social material y simbólica dentro del campo político. Su crítica a la teoría de la representación como ideología legitimadora del modelo de democracia liberal, se despega de un análisis meramente histórico o filosófico sobre su génesis normativa, para insertarse en el terreno de los problemas derivados de su instrumentación en sociedades contemporáneas desiguales y excluyentes, en las que la convergencia entre las lógicas política y económica constantemente favorecen nuevas fragmentaciones. En su denuncia de los intereses políticos, periodísticos e intelectuales que traman este escenario, Bourdieu sintetiza las condiciones de circulación ideológica de las prácticas democráticas en el marco de una noción activo-creativa de las mayorías, reconociendo tanto sus limitaciones estructurales como sus posibilidades 
disruptivas y productoras del cambio social. Así se aleja tanto de la fe individualista de las perspectivas políticas clásicas sobre la OP, como del prejuicio sobre la homogeneidad y pasividad de las mayorías, propio de una visión de la democracia que acompañó el surgimiento de la teoría de la sociedad de masas.

La concepción de la ciencia -y de la sociología política en particular- aportada por Bourdieu, muestra un compromiso profundo con las implicancias políticas de la actividad intelectual, superador de una mera oposición esterilizante entre criticismo y empirismo extremos. En su competencia con otras disciplinas interesadas en la producción de representaciones válidas sobre el mundo social, la sociología se convierte casi inevitablemente en una ciencia política, en la que "la lucha política es una lucha cognitiva (práctica y teórica) por el poder de imponer la visión legítima del mundo social" (Bourdieu, 1997, citado por Wacquant, 2005, p. 16). En definitiva, se trata del "poder de (re)hacer la realidad preservando o cambiando las categorías" por medio de las cuales los actores sociales comprenden y construyen su mundo. Bajo este enfoque, no solo la sociología debería preguntarse por el resultado de su compromiso político, sino también las ciencias sociales deberían "incluir dentro de la teoría del mundo social una teoría del efecto de la teoría" (Bourdieu, 2002, citado por Wacquant, 2005, p. 29). Aquí se advierte el peso del imperativo de reflexividad sobre la producción y política científica de Bourdieu, en la búsqueda de una constante vigilancia epistemológica del rol de los intelectuales como productores culturales.

Por último, al igual que su interés por "politizar las cosas sometiéndolas a la ciencia" (Poupeau y Discepolo, 2005, p. 82) marcaría una diferencia entre sociologismo y capacidad científica para producir "utopías fundadas sociológicamente", la disolución del dualismo agencia-estructura en su concepción de la acción social le permite a Bourdieu romper toda frontera analítica entre cultura y política. En su obra se advierte una sociología política de las formas simbólicas, sintetizadora de los aportes de 
tradiciones estructuralistas y constructivistas, en la cual el "principio de la acción no reside en ninguno de los dos 'estados de lo social' que constituyen las instituciones y los agentes, sino en su relación" (Wacquant, 2005, p. 162). Así, la comprensión sociológica de esquemas y disposiciones mentales o corporales se enfoca en la internalización de ciertas condiciones sociales, en tanto estructuras encarnadas desde la dialéctica campo-habitus. Superando tantas dicotomías como sea posible (teoría-praxis, objeto-sujeto, cultura-política), la tesis de una endogeneidad constitutiva de las estructuras sociales abonada por Bourdieu impulsa a la agenda de la investigación mediológica contemporánea a dejar de pensar la comunicación política de manera medio-centrada o sociocentrada, recuperando el papel del lenguaje en la producción del mundo social. Desde una crítica a enfoques meramente lingüísticos, entiende que las operaciones de nominación y los ritos de institución abonan el terreno de una "lucha de clasificaciones" en tanto "dimensión de toda lucha de clases" (Bourdieu, 2001, p. 65). Así, al igual que la inexistencia de la OP no es taxativa sino deviene de su simulación estadística, el discurso no desaparece dentro de la lógica analítica de Bourdieu, siendo valorado desde las condiciones sociales en que es (re)producido.

\section{Reflexiones finales: recapitulación sobre los términos de un fenómeno tan colectivo como censitario para la teoría sociológica contemporánea}

Para Habermas, las contradicciones que encarna el proyecto moderno de Estado de Derecho no son desconocidas, pero a diferencia de Bourdieu y Luhmann, son interpretadas desde una sociología reconstructiva e interpelativa del orden institucional, en pos de una actualización normativa de la relación entre los poderes administrativo y social, vía intermediación de la racionalidad comunicativa. Como podemos apreciar, para este autor la soberanía posee un contenido social que trasciende su inclusión 
dentro del discurso del contractualismo clásico y "se expresa en los derechos de comunicación y participación que aseguran la autonomía pública de los ciudadanos" (Habermas, 1999, p. 252). Aquí el planteo habermasiano se distancia de la sociología de la dominación de vertiente francesa, dado que, para el autor, no está en cuestión el carácter ideológico y los condicionamientos de esta autonomía, como tampoco su crítica se dirige a la inscripción de la política en los cuerpos y su dimensión simbólica o configuradora de identidad. Autonomía privada y pública, derechos humanos y soberanía popular son categorías normativas que se suponen recíprocamente dentro del enfoque de Habermas sobre el papel de la OP contemporánea, tornándose operativas al articularse por medio de una política deliberativa como mecanismo de integración social. Se observa entonces cómo la posibilidad de disenso para Luhmann supondría cierto riesgo democrático para Habermas, distanciándose sus respectivas imágenes contemporáneas de sociedad "compleja".

Por el contrario, desde la mirada sistémica de Luhmann, junto al incremento en la conflictividad se consolida una mayor tolerancia a la diversidad. El orden social contemporáneo ya no se produce en torno a núcleos normativos fuertes, sino a esquemas cognitivos más flexibles, y todo intento de recuperación de una moralidad compartida tiende a ser anacrónico y antimoderno. Esta redefinición funcional acompaña una fuerte crítica de Luhmann al supuesto de racionalidad como criterio analítico válido, presente tanto en las tradiciones psicosociales como político-normativas sobre la problemática de la OP -incluyendo proyectos reconstructivos como el de Habermas-. A nivel epistemológico, su postura se aproxima a la sociología reflexiva de Bourdieu, ya que no sólo propone posicionar el análisis desde otro lugar (la teoría sociosistémica), también reclama evaluar las condiciones de producción de las perspectivas teóricas asumidas. No obstante, cabe aquí objetar cierta lógica diluyente de poderes y responsabilidades que impregna la alusión de Luhmann a las operaciones sistémicas de los MMC, considerando que el autor omite el 
efecto de control social del cambio producido por la información bajo su tendencia falsamente novedosa. En su consideración sobre las implicaciones cognitivas de estos procesos masivos, tampoco incluye el papel de la ideología en las estructuras sociales, concentrándose en la reproducción sistémica del sentido social. Esta será una debilidad de su enfoque en comparación con otros proyectos de síntesis conceptual, como el de Bourdieu, cuya mirada sociológica adopta los procesos de dominación como eje de análisis.

Asimismo, la crítica de Luhmann a la obsolescencia de un planteo meramente consensual de la OP contemporánea, aproxima su planteo a la sociología política de Bourdieu, en cuanto al interés de este último por identificar las condiciones sociales de posibilidad de las instituciones políticas, con independencia de los ideales normativos que acompañaron su surgimiento histórico. Distanciándose del planteo reconstructivo de Habermas, Bourdieu entiende a la sociología política simultáneamente como crítica sociológica de la política y crítica epistemológica de la ciencia política. Decidido a profundizar este desafío a la comodidad intelectual de la academia, para Bourdieu, "en el fondo, la sociología tiene el mismo objeto que la política pero las mismas reglas de validación de la ciencia" (Bourdieu, 2002, p. 74). Aquí puede advertirse que el autor habla de opinión colectiva en tanto constructo deseablemente superador de la OP, desarrollada como artefacto de dominación simbólica, y sitúa su formación en el nivel intergrupal de la acción social dentro del campo político. En este punto podría establecerse una sutil conexión entre su planteo y la propuesta deliberativa de Habermas, al considerar idealmente válidos los intercambios reglados derivados de la confrontación dialéctica. Sin embargo, luego su planteo vuelve a distanciarse, ya que Bourdieu no pone énfasis en la razón como instrumento de acuerdo y entiende también al desacuerdo como posibilidad, aproximándose a las alternativas funcionales previstas por Luhmann para la OP, en tanto subsistema clave para la reproducción del sistema político. 


\section{Referencias}

Boladeras Cucurella, M. (2001). La opinión pública en Habermas. Analisi: quaderns de comunicacio i cultura, 26, 51-70.

Bourdieu, P. (2012). Cómo se forma la opinión pública. Le Monde diplomatique, 151. Recuperado el 3 de marzo de 2015, de http:/ / www.eldiplo.org/notas-web/como-se-forma-la-opinionpublica.

Bourdieu, P. (2005). El misterio del ministerio. De las voluntades particulares a la 'voluntad general'. En L. Wacquant (coord.). (2005). El misterio del ministerio. Pierre Bourdieu y la politica democrática, 71-79. Barcelona: Gedisa.

Bourdieu, P. (2002). Pensamiento y acción. Buenos Aires: Libros del Zorzal.

Bourdieu, P. (2001). ¿Qué significa hablar? Madrid: Ediciones Akal.

Bourdieu, P. (1973). La opinión pública no existe. Les temps modernes, 318, 1292-1309. Recuperado el 3 de marzo de 2015, de http:/ / sociologiac.net/biblio/Bourdieu_OPE.pdf.

Champagne, P. (2005). "Hacer hablar a la gente. El uso social de las encuestas de opinión pública en democracia". En L. Wacquant (coord.). (2005). El misterio del ministerio. Pierre Bourdieu y la política democrática, 111-133. Barcelona: Gedisa.

Habermas, J. (1999). La inclusión del otro. Estudios de teoría politica. Barcelona: Paidós.

Habermas, J. (1998). Facticidad y validez. Sobre el derecho y el Estado democrático de derecho en términos de una teoría del discurso. Madrid: Trotta.

Habermas, J. (1981). Historia y crítica de la opinión pública. La transformación estructural de la vida pública. Barcelona: Gustavo Gili.

Luhmann, N. (2007) [1990]. La realidad de los medios de masas. BarcelonaMéxico: Anthropos - Universidad Iberoamericana.

Luhmann, N. (1995) [1986]. La autopoiesis de los sistemas sociales. Zona Abierta, 71, 21-51.

Maigret, É. (2005). Sociología de la comunicación y de los medios. Bogotá: FCE.

Poupeau, F. y Discepolo, T. (2005). "Investigación y compromiso. La dimensión política de la sociología de Pierre Bourdieu". En 
L. Wacquant (coord.). (2005). El misterio del ministerio. Pierre Bourdieu y la política democrática, 81-109. Barcelona: Gedisa.

Rabotnikof, N. (2005). En busca de un lugar común. El espacio público en la teoría política contemporánea. México: Universidad Nacional Autónoma de México.

Wacquant, L. (coord.). (2005). El misterio del ministerio. Pierre Bourdieu y la política democrática. Barcelona: Gedisa. 
